\title{
Chemical vapor deposition of pyrolytic carbon on polished substrates
}

\author{
J.-F. DESPRÉS, C. VAHLAS and A. OBERLIN \\ Laboratoire Marcel Mathieu, UMR 124, CNRS-DRET-UPPA, Centre Hélioparc, 2 avenue Angot, \\ 64000 Pau, France
}

\begin{abstract}
Pyrolytic carbon thin (4-100 nm) films were obtained from methane in a hot wall reactor on optically polished inert substrates by varying the deposition time and temperature. They were characterized by all modes of TEM. They are composed in majority of lamellar pyrocarbon whose thickness and disorder increases with increasing temperature. Isotropic carbon islands are also observed at the upper surface of the film.
\end{abstract}

\section{Introduction}

The pyrolysis of methane is a dehydrogenation process which leads to the growth of solid carbon named pyrocarbon, (PC), of various micro- and nanotextures and structures and, according to the operating conditions, to solid, liquid or gaseous hydrocarbons of various molecular weights. The abundant data available in the literature on this complex-chemistry process, (1-5), correspond essentially to high temperature $\left(\sim 2000^{\circ} \mathrm{C}\right)$ or porous media deposition and do not fit each other. This lack of reproducibility is mainly due to the use of complex geometry substrates to be infiltrated (felts, tissues etc.) or to the use of fluidized bed reactors. In both cases, the gas phase diffusion gradients and the surface kinetics play a predominant role. Consequently, the experimental parameters in the vicinity of the deposition surface, like the gas phase temperature and composition, cannot be controlled. For example, it was shown that the variation of the density of carbon fibers to be infiltrated drastically changes the texture of the pyrocarbon (3). Additionally, the influence of the chemical nature of the substrate and particularly of carbon on the quality of the deposit is suspected (4), but not evidenced yet.

The numerous kinds of PC described up to now, roughly correspond to the combination of three main microtextures: rough laminar (RL), smooth laminar (SL) and isotropic (I). This arbitrate classification comes from the first studies of pyrocarbon by optical microscopy (OM) (6). The cauliflower microtexture was responsible for the RL name, though the nanotexture determined by transmission electron microscopy (TEM) was that of lamellae. On the contrary, the absence of any visible texture in OM led to the SL name. However, in TEM the micro- and nanotextures are those of flattened pores. The isotropic PC is always nanoporous with pores randomly distributed.

The only way to illustrate the adequation between growth conditions and the kind of PC deposits is to avoid the physical (pores, rugosity) and chemical (carbon) influence of the substrate. In these conditions, by studying the very first steps of growth, it would perhaps be possible to choose between the various theories already proposed for the formation of PC: either the homogeneous-nucleation-based theory (formation of droplets further deposited on the substrate) proposed by Sweitzer et al. (7), or the direct deposition of carbon species on the substrate proposed by Tesner et al. (8). 
The present paper is the first step of an attempt to establish on a general basis the influence of growth conditions on the structure and nanotexture of PC. The up to now work included deposition temperature and time as the investigated experimental parameters, and was supported by $\mathrm{OM}$, atomic force microscopy (AFM), all modes of TEM observations and Auger electron spectroscopy (AES). Among these characterizations, only TEM and punctual laser optical diffraction observations will be illustrated in the following. The complete study will be presented later on (9).

\section{Experimental}

N55 pure $\mathrm{CH}_{4} 3 \%$ diluted in N56 pure Ar fed through separate mass flows an horizontal hot wall silica reactor operating at atmospheric pressure. $2 \mathrm{~cm}$ diameter optically polished alumina wafers were used as substrates. They were introduced into the reactor parallel to the gas flow and the operating temperature was set. The carbon containing deposits on the hot parts of the reactor from the previous run were thus burned. $970 \mathrm{sccm}$ Ar flow was then set for $30 \mathrm{~min}$ and finally deposition begun by setting an additional flow of $30 \mathrm{sccm} \mathrm{CH}$. At the end of deposition, methane flow was stopped and the reactor was cooled under Ar flow. Table 1 presents the films obtained or not as a function of deposition temperatures and times. Since in this paper only the very first steps of the deposition are studied, we will confine to the characterization of the $1050^{\circ} \mathrm{C} 240 \mathrm{~min}, 1100^{\circ} \mathrm{C} 30 \mathrm{~min}$ and $1200^{\circ} \mathrm{C} 2.5 \mathrm{~min}$ films, shown as $\underline{\nabla}$ in Table 1 .

Table 1. PC deposit preparations. $\nabla$ : available for direct TEM observation. $\underline{\nabla}$. : studied films.

\begin{tabular}{|c|c|c|c|c|c|c|c|c|}
\hline $\mathrm{T}\left({ }^{\circ} \mathrm{C}\right) \downarrow, \mathrm{t}(\min ) \rightarrow$ & 2,5 & 5 & 15 & 30 & 45 & 60 & 120 & 240 \\
\hline 1000 & \multicolumn{8}{|c|}{ no deposit } \\
\hline 1050 & \multicolumn{7}{|c|}{ no deposit } & $\underline{\nabla}$ \\
\hline 1100 & \multirow{2}{*}{\multicolumn{3}{|c|}{ no deposit }} & $\underline{\nabla}$ & $\nabla$ & $\nabla$ & $\nabla$ & \\
\hline 1200 & $\underline{\nabla}$ & & $\nabla$ & $\bar{\nabla}$ & & & & \\
\hline
\end{tabular}

Thick deposits were spontaneously separated from the substrate by forming folded flakes which were clamped inside a folding grid to be observed. Thinner deposits $\left(1050^{\circ} \mathrm{C}-240 \mathrm{~min}\right.$ and $\left.1100^{\circ} \mathrm{C}-30 \mathrm{~min}\right)$ remained firmly attached to silica. They were removed by floating on water surface and then picked up on a grid covered with a carbon supporting film. Films were characterized by selected area electron diffraction (SAD), bright field (BF), hkl tilted dark fields (hklDF) and carbon layers imaging, i.e. 002 lattice fringes (LF). The images obtained from each kind of the above TEM observations yield different informations on the structure and nanotexture of the characterized material. The way of use them concerning carbon films is developed in (10).

\section{Results}

\subsection{Features common to all deposits}

All deposits were composed of a highly oriented lamellar PC parallel to the surface of the substrate. On the upper surface of this major component, islands of other type of $\mathrm{PC}$ have grown. This situation is illustrated in the $\mathrm{BF}$ photograph of figure 1 taken from above the free (upper) surface of the $\left(1100^{\circ} \mathrm{C}, 30 \mathrm{~min}\right)$ deposit. The islands are presented here as dark dots grown above an homogeneously extended flat area.

The film is thin and flexible enough to fold from place to place, as for example in the lower part of the figure, where a fold running from left to the right is presented, with a strong dark contrast. In the 002DF 


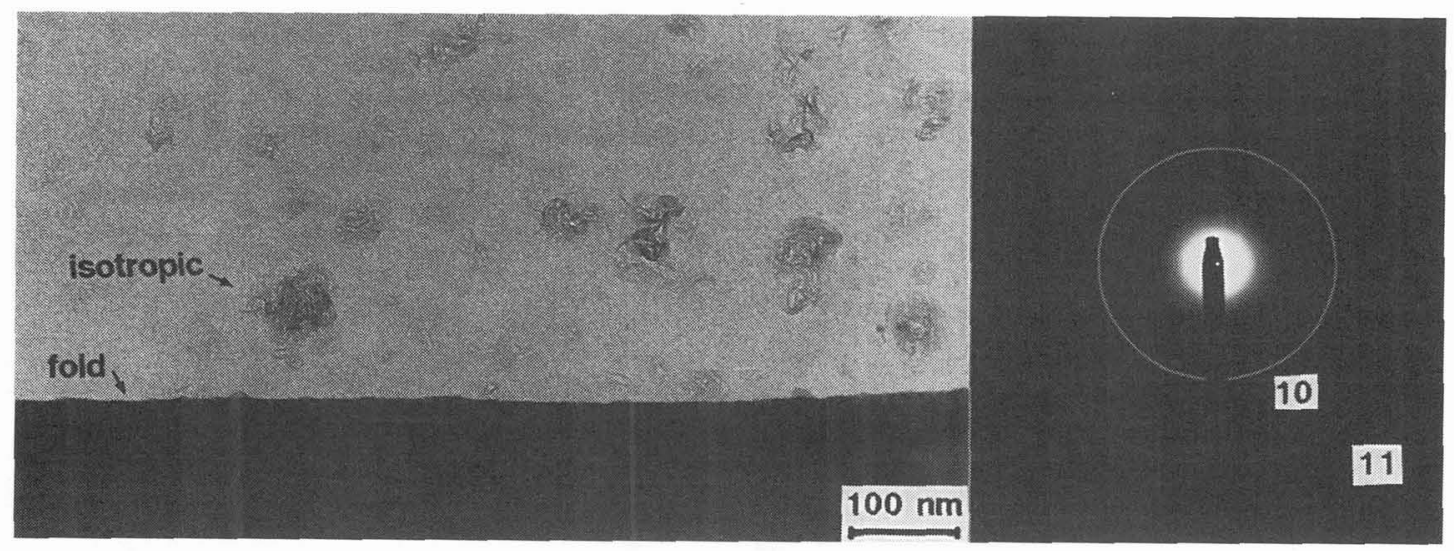

Figure 1. $\mathrm{PC}$ thin film deposited at $\mathrm{T}=1100^{\circ} \mathrm{C}$ and $\mathrm{t}=30 \mathrm{~min}$. BF image perpendicular to the surface of the substrate showing deposition islands at upper surface of the deposit and a fold of the film. A SAD pattern of the flat part of the film is shown in the inset on the right.

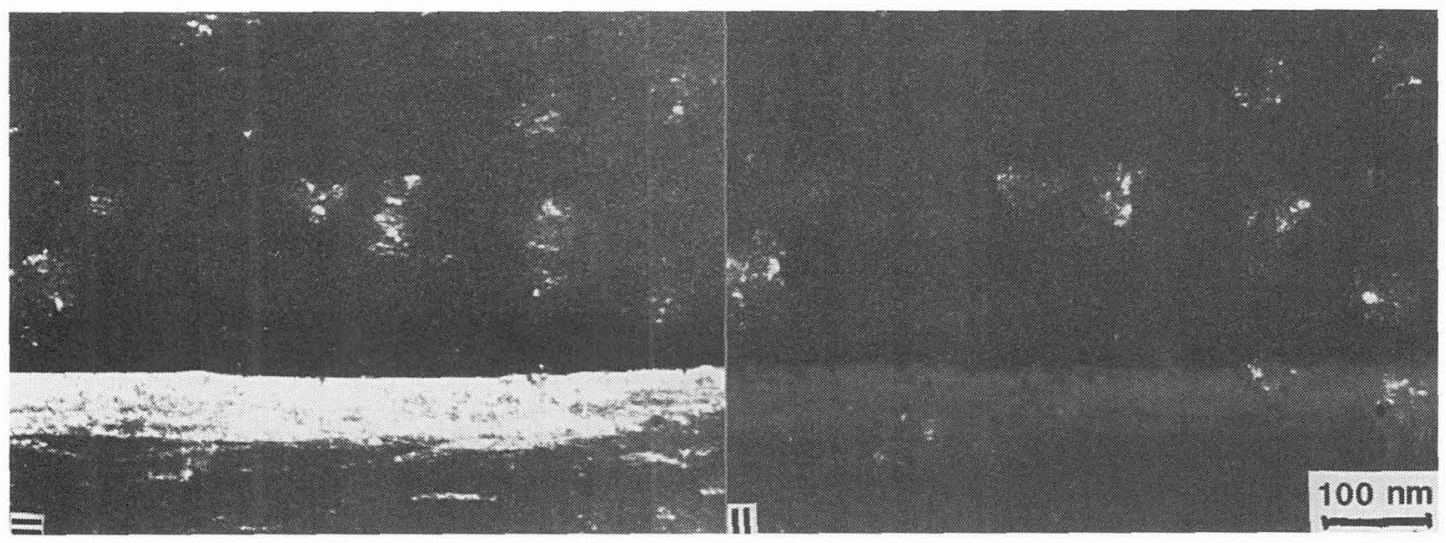

Figure 2. $\mathrm{PC}$ thin film deposited at $\mathrm{T}=1100^{\circ} \mathrm{C}$ and $\mathrm{t}=30 \mathrm{~min} .002 \mathrm{DF}$ images of the fold presented in figure 1 and the surrounding flat part following two directions of the aromatic planes, perpendicular to each other as indicated by the double bars.

of the same area, presented in figure $2 a$, the fold appears bright. The aromatic layer stacks are thus in majority parallel to the double bar. On the contrary, in figure $2 b$, where the double bar is oriented with a $90^{\circ}$ rotation, the fold is completely dark. The deposit is thus strongly oriented along the plane of the substrate. The majority of the flat area of figure 1 appears dark in figures $2 a$ and $2 b$, indicating that there is no stack seen edge on in this area. This is confirmed from the SAD pattern of the flat part of figure 1 , where the 002 reflections are absent, only the $10(0)$ and 11(0) rings being evidenced. Occurrence of preferred orientation exclusively along the substrate for the PC is thus illustrated. Figure 3 shows three high resolution image of the aromatic layers $(002 \mathrm{LF})$, seen parallel to the surface of the substrate for deposits at $1050^{\circ} \mathrm{C}(3 \mathrm{a}), 1100^{\circ} \mathrm{C}(3 \mathrm{~b})$ and $1200^{\circ} \mathrm{C}(3 \mathrm{c})$. The high quality of the orientation is illustrated. 


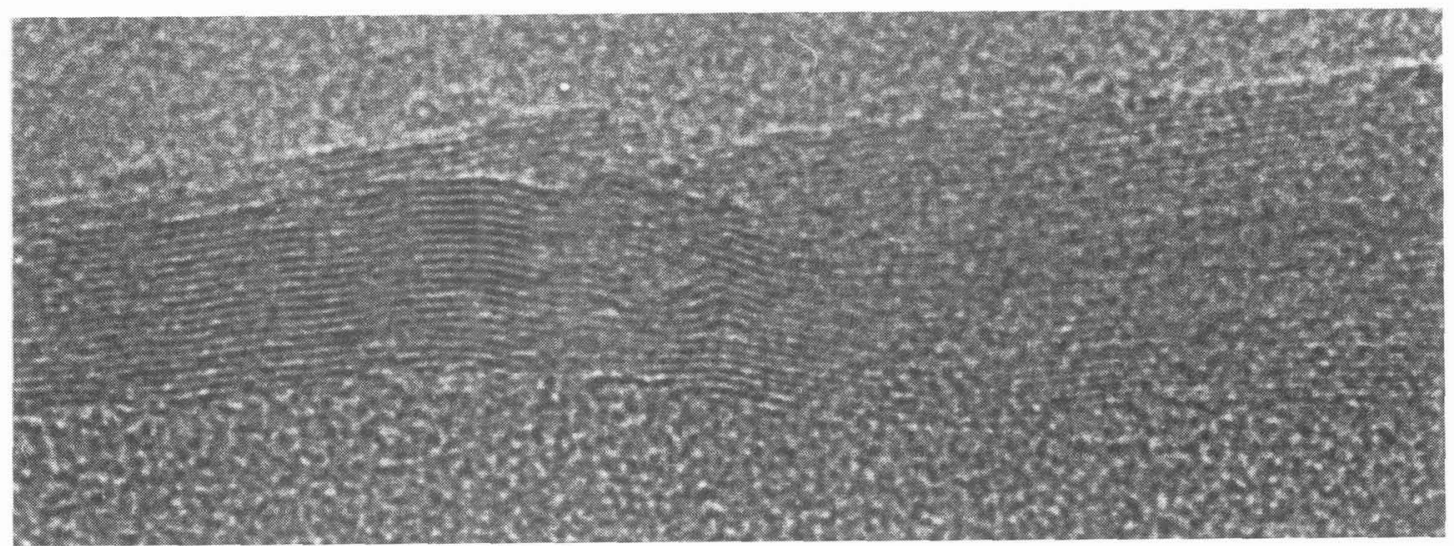

a

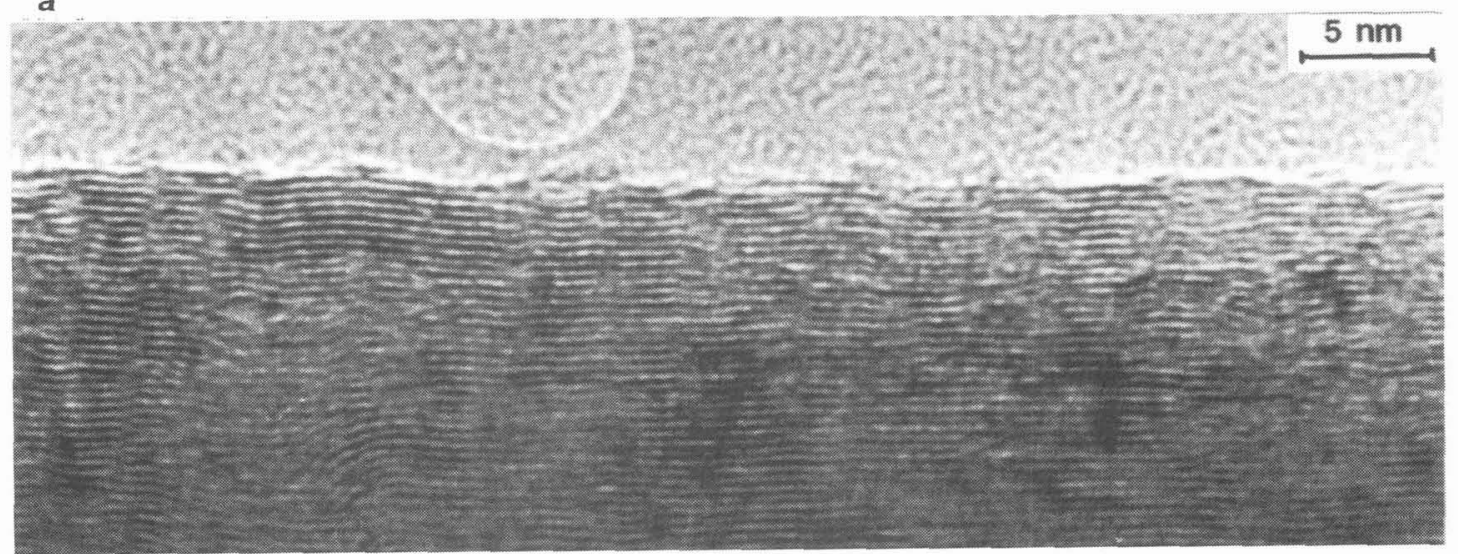

b

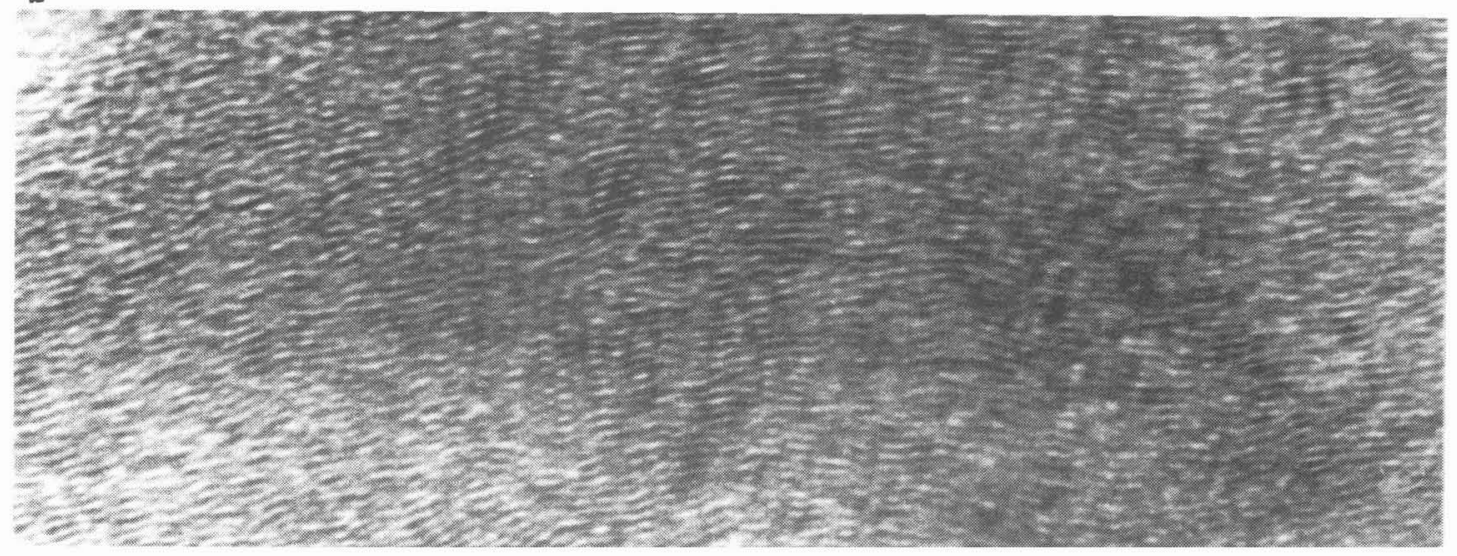

c

Figure 3. $002 \mathrm{LF}$ images of $\mathrm{PC}$ thin films seen edge on, deposited at $\mathrm{T}=1050^{\circ} \mathrm{C}$ and $\left.\mathrm{t}=240 \mathrm{~min}\right)(3 \mathrm{a}), \mathrm{T}$ $=1100^{\circ} \mathrm{C}$ and $\mathrm{t}=30 \mathrm{~min}(3 \mathrm{~b})$, and $\mathrm{T}=1200^{\circ} \mathrm{C}$ and $\mathrm{t}=2.5 \mathrm{~min}(3 \mathrm{c})$. 
Additionally, no pores whether flattened or not were found, indicating the high compactness of the deposited PC.

The AFM characterization of the upper surface of the oriented lamellar PC showed corrugations by round-in-shape islands. They appear darker in BF (Figure 1) and as short bright bands indicating aromatic layer stacks oriented edge on, in 002DF (Figure 2). These bands are the images of pore walls oriented at random, i.e. whatever is the double bar orientation, bright bands occur. In a 002LF image of such an island as the one of figure 4, nanopores appear (arrows). Since no nucleus could be detected inside the pores, it is not possible to suspect the occurrence of soot of any kind. The above observations associated to characterization of accidentally formed soots (9), lead to the firm conclusion that these corrugations (which are equivalent to the ones observed in AFM), correspond to isotropic PC islands representing the end of carbon deposition.

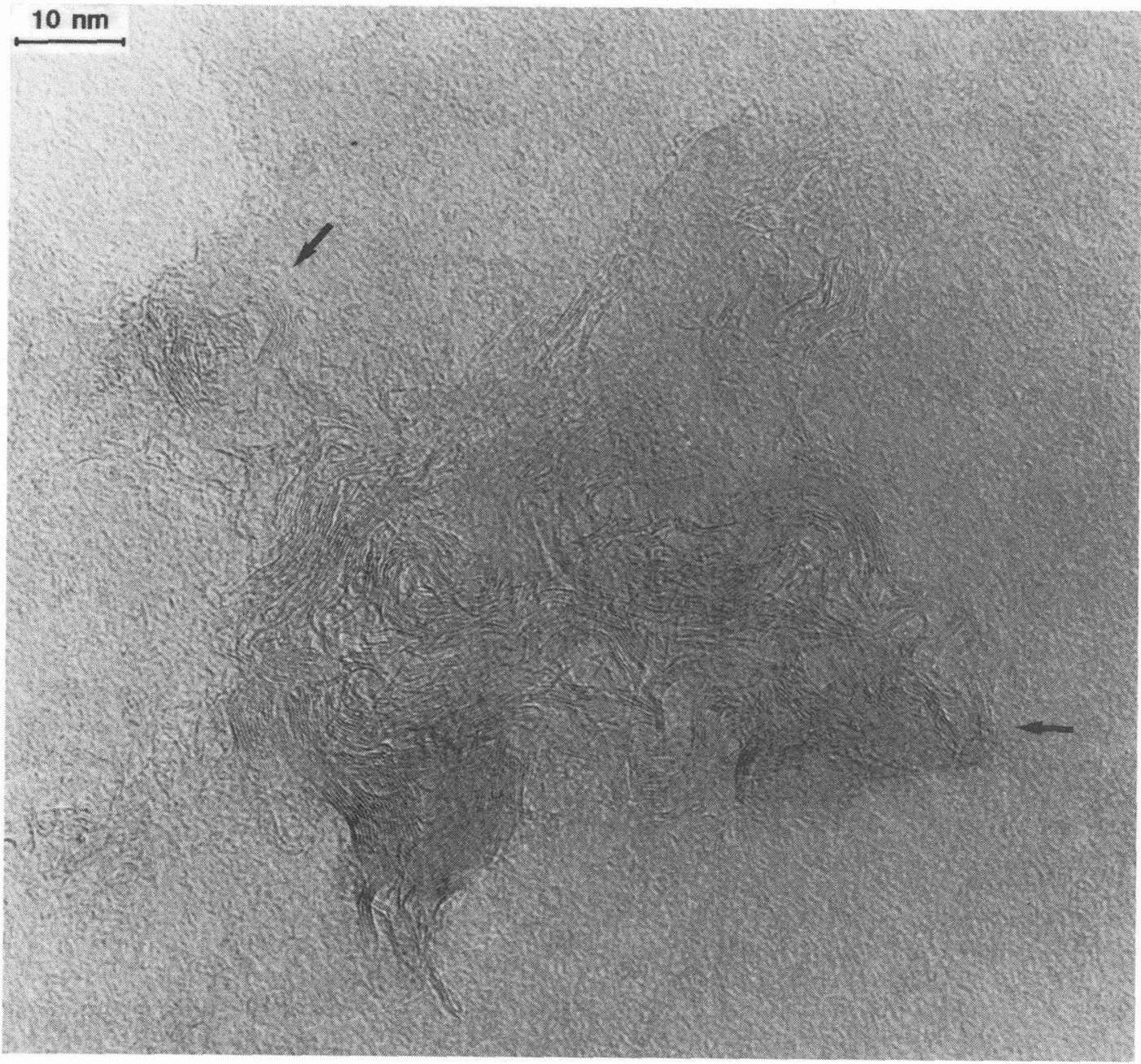

Figure 4. PC thin film deposited at $\mathrm{T}=1050^{\circ} \mathrm{C}$ and $\mathrm{t}=240 \mathrm{~min} .002 \mathrm{LF}$ image of an isotropic island on the upper surface of the lamellar deposit. 


\subsection{Evolution with deposition temperature and time}

The thickness of the deposited films was evaluated by AFM, shadow-casting in TEM and direct observation in TEM. From these measurements an average value was deduced and adopted.

The thickness of the isotropic islands increases moderately with temperature. It is approximately 10 $\mathrm{nm}$ for $1050^{\circ} \mathrm{C}, 25 \mathrm{~nm}$ for $1100^{\circ} \mathrm{C}$ and $30-40 \mathrm{~nm}$ for $1200^{\circ} \mathrm{C}$. Their density remains unchanged between $\left(1050^{\circ} \mathrm{C} 240 \mathrm{~min}\right)$ and $\left(1100^{\circ} \mathrm{C} 30 \mathrm{~min}\right)$ but they seem to spread on the surface of the lamellar PC as temperature increases. At $\left(1200^{\circ} \mathrm{C} 2.5 \mathrm{~min}\right)$ they almost join each other as it appears in BF in figure 5 . It thus appears that their development corresponds to an increase in diameter rather than in number. In the SAD pattern of the corresponding flat part of the deposit also shown in figure 1 , only the $10(0)$ and $11(0)$ rexlexions are evidenced, the $00 t$ reflexions being absent.

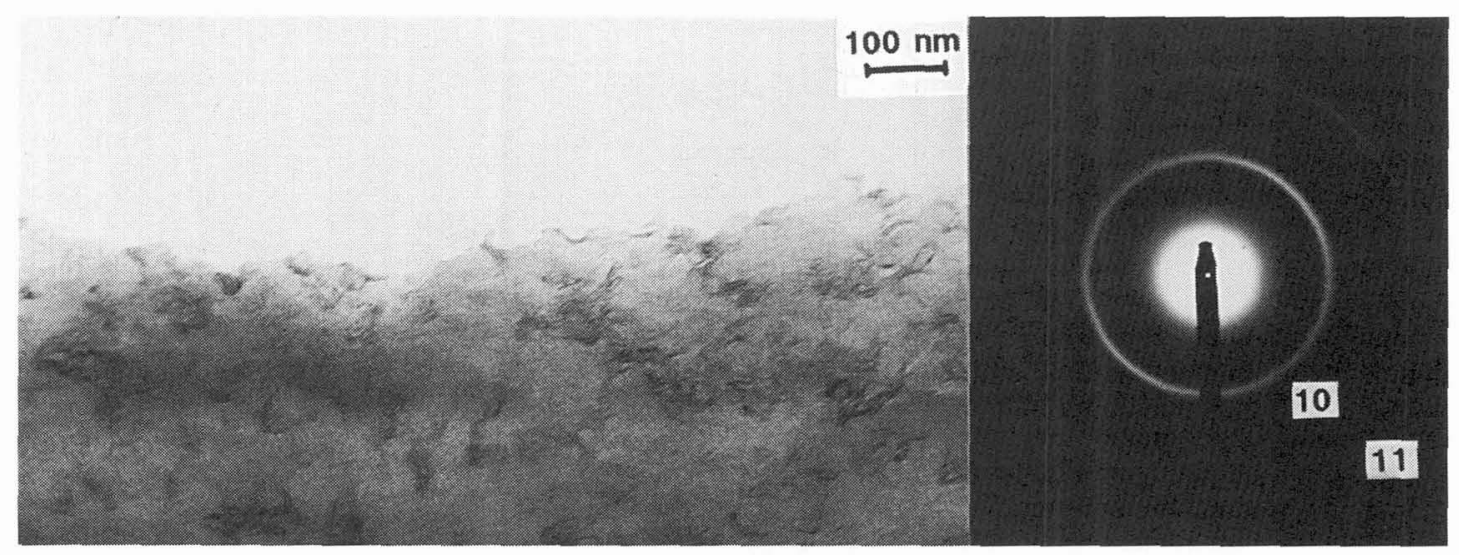

Figure 5. PC thin film deposited at $\mathrm{T}=1200^{\circ} \mathrm{C}$ and $\mathrm{t}=2.5 \mathrm{~min}$. $\mathrm{BF}$ image perpendicular to the surface of the substrate showing deposition islands at upper surface of the deposit. A SAD pattern of the flat part of the film is also shown.

The thickness of the lamellar PC increases with deposition temperature and time from 4-5 nm at $\left(1050^{\circ} \mathrm{C}, 240 \mathrm{~min}\right)$ up to $100 \mathrm{~nm}$ at $\left(1200^{\circ} \mathrm{C}, 2.5 \mathrm{~min}\right)$.

From the comparison of the SAD patterns of figures 1 and 5 it appears a widening of the $10(0)$ and $11(0)$ rings when increasing the deposition temperature from 1100 to $1200^{\circ} \mathrm{C}$. The width of each ring can be associated with the inverse of $\mathrm{La}$, which is the extent of the coherently scattering domains of PC. Consequently, this evolution corresponds to a decreasing of $\mathrm{La}$ which is thus measured to be $4.5 \mathrm{~nm}$ and $1.6 \mathrm{~nm}$ for the $1100^{\circ} \mathrm{C}$ and the $1200^{\circ} \mathrm{C}$ films, respectively. Between the $1050^{\circ} \mathrm{C}$ and the $1100^{\circ} \mathrm{C}$ films no significant evolution of La was evidenced.

Order of the lamellar films following the pseudo-c axis also decreases in the same way, with increasing temperature. This evolution can be observed in the three LF images of figure 3 concerning essentially the number and length of fringes in a stack. It seems that both of them decrease with increasing temperature. This is also confirmed and quantified by the three laser optical diffraction patterns of figure 6 . These patterns are produced with an monochromatic laser beam passing through the aromatic layers area of negative TEM plates as those corresponding to the photographs of figure 3 . Two parameters change in the three optical diffraction patterns of figure 6: The width of the symmetrical spots which increases with deposition temperature and the distance of the maximum at each spot from the center i.e. from the non diffracting beam, which decreases with deposition temperature. The first parameter indicates a decrease of 
$\mathrm{N}$, the number of fringes in a stack, which passes from $9-10$ for the $\left(1050^{\circ} \mathrm{C}, 240 \mathrm{~min}\right)$ deposit, down to 6 for the $\left(1200^{\circ} \mathrm{C}, 2.5 \mathrm{~min}\right)$ deposit. The second parameter corresponds to the inverse of the distance between neighbour aromatic layers which is $0.361 \mathrm{~nm}$ for the $\left(1050^{\circ} \mathrm{C}, 240 \mathrm{~min}\right)$ deposit and 0.382 for the $\left(1200^{\circ} \mathrm{C}, 2.5 \mathrm{~min}\right)$ deposit. The comparison of these distances to the one in graphite, i.e. the perfectly organized configuration of carbon, which is $0.335 \mathrm{~nm}$, reveals a deterioration of the degree of order in the deposits by increasing the deposition temperature. Simultaneously, a rough evaluation of the relative disorientation of the coherent domains can be obtained, which is proportional to the arc opening in the optical diffraction pattern. Even if it appears from the comparative study that qualitatively there is indeed an increase of the relative disorientation from $1050^{\circ} \mathrm{C}$ up to $1200^{\circ} \mathrm{C}$, care must be taken in the interpretation of these results, since ondulations of the aromatic layers yield similar results.
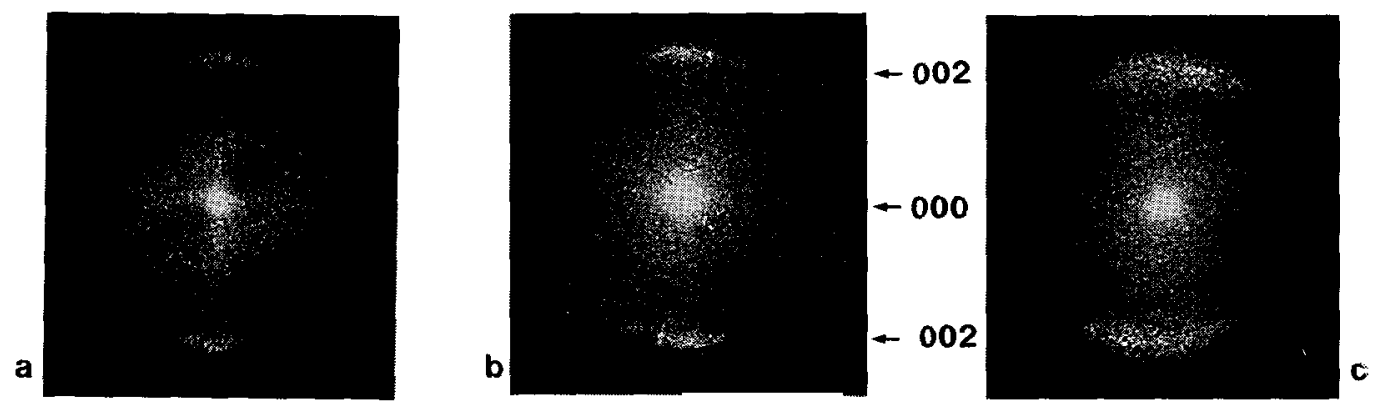

Figure 6. Laser optical diffraction images of $\mathrm{PC}$ thin films seen edge on. The sequence corresponds to the one of figure 3: Deposition at $\mathrm{T}=1050^{\circ} \mathrm{C}$ and $\mathrm{t}=240 \mathrm{~min}(\mathrm{a}), \mathrm{T}=1100^{\circ} \mathrm{C}$ and $\mathrm{t}=30 \mathrm{~min}(\mathrm{~b})$, and $\mathrm{T}=$ $1200^{\circ} \mathrm{C}$ and $\mathrm{t}=2.5 \mathrm{~min}(\mathrm{c})$.

\section{Concluding remarks}

Compact deposits with no flattened pores were systematically observed in all TEM images at different magnifications. This remark, associated with OM observations indicating no cauliflower microtexture [9], allows for the conclusion that the lamellar carbon is neither a smooth nor a rough laminar PC. The morphology of the deposited films looks similar to the one of turbostratic carbon films graphitized above $2100^{\circ} \mathrm{C}$ [11]. The order of this lamellar carbon is particularly high considering the deposition temperature, as compared to the texture of high temperature massive pyrocarbons presented for example in [4]. This may be due to the very low deposition rate and thickness of the deposits, allowing for a slow deposition with reduced constraints incorporated in the films. This reason can also explain the decrease of order of the lamellar PC as temperature increases. This phenomenon seems a priori opposite to the established graphitization trends which indicate an increase of order of carbon layers with temperarure. However it must be considered that the deposition temperature of the present study corresponds rather to the initial step of slow fabrication of the material, than to a post deposition (carbonisation or graphitization) treatment temperature.

Their position opposite to the surface of the substrate as well as the small quantity of matter which is systematically implicated, indicates that isotropic islands represent the end of carbon deposition. It is possible but not yet established that this nanotexture is due to the progressive degradation -if any- of the order of the lamellar PC with the deposition time, i.e. along the width of the deposit, or the distance from the substrate. 
In any way, the morphology of the deposited films clearly shows that in the adopted operating conditions, an heterogeneous nucleation mechanism controls the first steps of the process. From the above it appears that it would be interesting to study the evolution of the activation energy as a function of temperature and/or time in order to evidence changes of the deposition mechanisms which can lead to an evolution of the nanotexture within the heterogeneous nucleation regime.

\section{SUMMARY}

The very first steps of chemical vapor deposition of pyrolytic carbon were studied in a hot wall reactor starting from methane, for deposition temperatures between $1050^{\circ} \mathrm{C}$ and $1200^{\circ} \mathrm{C}$. Thin $(4-100 \mathrm{~nm})$ films were deposited on optically polished inert substrates and were characterized by all modes of TEM. They are composed in majority from lamellar pyrocarbon whose nanotexture looks similar to the one of turbostratic carbons graphitized above $2000^{\circ} \mathrm{C}$. Their thickness and disorder increases with increasing temperature.

Isotropic islands were also observed at the upper surface of the film corresponding to the latest steps of deposition. Their density remains unchanged but their extent on the lamellar PC increases with deposition temperature. Further investigation of the deposition mechanisms and nanotexture of the deposited films, associated with the deposition time and the concentration of methane in the initial gas phase are in progress.

\section{ACKNOWLEDGEMENTS}

The Société Européenne de Propulsion (SEP) is acknowledged for providing a grant to one of the authors (JFD).

\section{REFERENCES}

[1]. Bokros J. C., Chemistry and Physics of Carbon, 5 (1969) 1.

[2]. Loll P., Delhaes A., Pacault A., Pierre A., Carbon, 15(6) (1977) 383.

[3]. Delhaes A., Tringuecoste M., Pacault A., Goma J., Oberlin A., Thebault J. Carbon 84, Bordeaux, France (1984) 192.

[4]. GOMA J., OBERLIN A., Carbon, 23(1) (1985) 85.

[5]. GOMA J., OBERLIN A., Carbon, 24(2) (1986) 135.

[6]. LIEBerman M.L., Pierson H.O., Carbon, 12 (1974) 233.

[7]. SWEITZER C.N., HELLER G.L., Rubber World, 134 (1956) 855.

[8]. TESNER P.A., Symp. Combust. 7th, Oxford, GB (1958) 546.

[9]. DESPRES J.F., OBERLIN A. To be published in Carbon.

[10]. OBERLIN A., GOMA J., ROUZAUD J.N., Journal de Chimie Physique, 81(11/12) (1984) 701.

[11]. GOMA J., OBERLIN A., Thin Solid Films, 65 (1980) 221. 